\title{
Research on Social Psychology Based on Network Big Data
}

\author{
Fuhong Li \\ Department of psychology, Weifang Medical University, Weifang, Shandong 261053, China \\ Email: lfhpsy@163.com
}

Keywords: big data, social psychology, blog-emotion, network.

\begin{abstract}
Previous social psychology is usually based on questionnaires, data statistics, sample surveys and laboratory studies to analyze mental data, and in the era of big data, real, accurate and timely large data samples will bring new opportunities for changes in social psychology research methods. In recent years, around the network of large data, social psychology research has shown great development potential. The big data helps researchers to test the classical assumptions of some of the psychology through network data to provide new evidence for theoretical hypotheses and arguments. In the network environment, domestic researchers should pay more attention to explore the network with big data on the psychological and behavioral problems when do the research of the individual psychological, social adaptation mechanism. This is of great significance for the timely discovery and resolution of social problems.
\end{abstract}

\section{Introduction}

The arrival of the network information age not only has changed people's way of life, but also brought profound changes to the academic research paradigm. The real world and the network world are closely related, and the traces of human behavior is in the form of a large number of data. Psychological researchers increasingly rely on computer and information science and technology to explore the individual or group of psychological and behavioral laws. While, social psychology is a scientific method to study people's thoughts, emotions and behavior how to be influenced by a subject. It is oriented by the social phenomenon and aims to explore the individual and group social psychological phenomenon of the occurrence, development and laws, even has a deep understanding of social groups behind the motives and purposes. In the 1970s, psychologists began to use the computer to implement specific psychological experiments and in the 1990s, the birth of the network based on the network, as well as the establishment of a virtual network psychology laboratory has made social psychology usher a great change. Big data samples are gradually becoming a valuable resource for researchers to observe and predict the characteristics and laws of individual and group psychological behavior. It is foreseeable that big data will bring about change and challenge for the development of social psychology.

The combination of psychology and big data of the network not only provides a broader platform and opportunity for the traditional psychology to explore the psychological and behavioral mechanisms of the individual level through the representative large sample, but also provided the possibility for the deep excavation of large-scale crowd in the group of psychological behavior law. In recent years, in the cooperation and joint efforts of psychology and other social science and information science researchers, many areas of social psychology has made a number of representative research results. Therefore, the study of social psychology of big data on the network, the future researchers should rationally look at this emerging research paradigm, and give full play to the advantages of the paradigm, so as to better solve the social science theory and practical social problems. With the help of big data, social psychology can largely get rid of dependence on the physical laboratory, the maximum and most efficient expansion of the potential research object will realize. Thus social psychology research is no longer confined to a small laboratory sample or the 
random samples collected by questionnaire, instead, we are approaching the overall sample as much as possible, which makes the basis of social psychology research has undergone enormous changes. At the same time, big data can also provide a more diversified and heterogeneous approach to social psychology research.

\section{The Development of Big Data and Social Psychology}

Big data technology is used to collect and analyze huge amounts of data. This technology performs a comprehensive analysis and processing for all the data resources, and then provides a strong support effect for the specific objectives and tasks, which is different from the random analysis method[1]. The extensive application of the network and the intertwined with reality not only change the way of life, but also promote the transformation of academic research paradigm. On the one hand, mass Internet users with microblogging, forums and other social media products and mobile Internet tools to record their own lives, so social networking sites, books, traditional blog, SMS and mobile App are likely to become a source of large psychological data. And even so, social psychologists have begun to use a variety of platforms to obtain big data information, and the use of linguistic theory and mathematical methods for a number of studies. For example, Daniel T. Gilbert, a social psychologist, and his students have developed a mobile App that allows people to report real-time thoughts, emotions and events. They collected 86 class activities from 83 countries, and the age raged from 18 to 88 years old[2]. And they found that the happiest thing is sex, exercise, chat, games and listening to music. Moreover, compared to unhappy events, happiness is usually something that people are more attentive to do, which are similar to the traditional research findings. Therefore, big data is not just a change in the way of psychology data collected and is not the data driven by statistical analysis. It is not equivalent to social media. It does not just study the increase in subjects. Big data, at the same time, has brought changes to the psychological theory and psychological research thinking. Psychology is devoted to the study of human psychology and behavior. At the micro level, the new research method will bring new research questions; but at the macro level, psychology is still exploring the nature of human nature and human psychology. Improvement of the reform is not to bring the subject of research on the nature of the changes, but it provides a disciplinary norms, to bring a discipline-specific research channels and the fundamental way of thinking.

\section{Research Practice of Social Psychology Based on Big Data}

\section{The benifits for social psychology}

Big data declares the era of prediction of social psychology, because the social psychology research based on big data age is no longer dependent on random sampling, but by processing and analysis of relevant data to obtain conclusions, which helps to improve the prediction ability. For example, the predictions of mental health can be used to replace the answers collected through the questionnaire, and the method of machine learning is used to establish the mental health prediction model based on network behavior[3, 4]. The mental health status score of the subjects is calculated by the model. Besides, the prediction of happiness can predict the happiness of the public and the prediction of social mentality, social risk judgment, group sentiment and cluster behavior, economic development confidence and government trust can predict and evaluate the social attitudes of the people. Group of social attitudes of the time changes in the determination of social public opinion, and guide the public opinion.

China's social psychology researchers have been on the Chinese microblogging emotional online measurement and application issues, try to work with the field of information science researchers to carry out a series of research and exploration. One achievement of big data for social psychology is the development of microblogging emotional measurement tools. Microblogging accumulation of mass information provides the possibility for the direct measurement of large-scale crowd attitude and social sentiment. The online text can be a tool for emotional analysis, so applying the emotional 
research results in the field of psychology on online text analysis technology can be real-perceive the public's social mood changes.

\section{The risk of big data for social psychology}

Based on hot business background of big data, how to objectively and rationally look at large data research is also a question worthy discussing. At present, there are two views on the big data, one is that big data is omnipotent, and the use of large data research method is high quality research. The other is that big data is useless, and the data is not accurate, even the result is pseudo-related. Objectively speaking, big data is more like a new paradigm or new method, it has its own advantages, such as large sample size, high ecological efficiency. Big data also have some shortcomings, including inaccurate, low reliability, difficult to reveal causality and other issues. In addition, the characteristics of big data is difficult to ensure that the causal relationship between the inference. To study the cause and effect by big data is more difficult. The cause and effect found in many large data studies is only statistically significant. And, most importantly, as big data is widely used in scientific research, business and management and many other areas, people have a great suspicion of their privacy. People's search records, shopping records on e-commerce sites, interactive records with friends in social media have been mastered by network service providers. The security of these data has become a network of information society a major risk. Figure 1 provides the attitude for privacy of different income groups[6, 7]. Data privacy risks caused a large discussion of the community, the world has begun to build and improve the data privacy protection related laws.

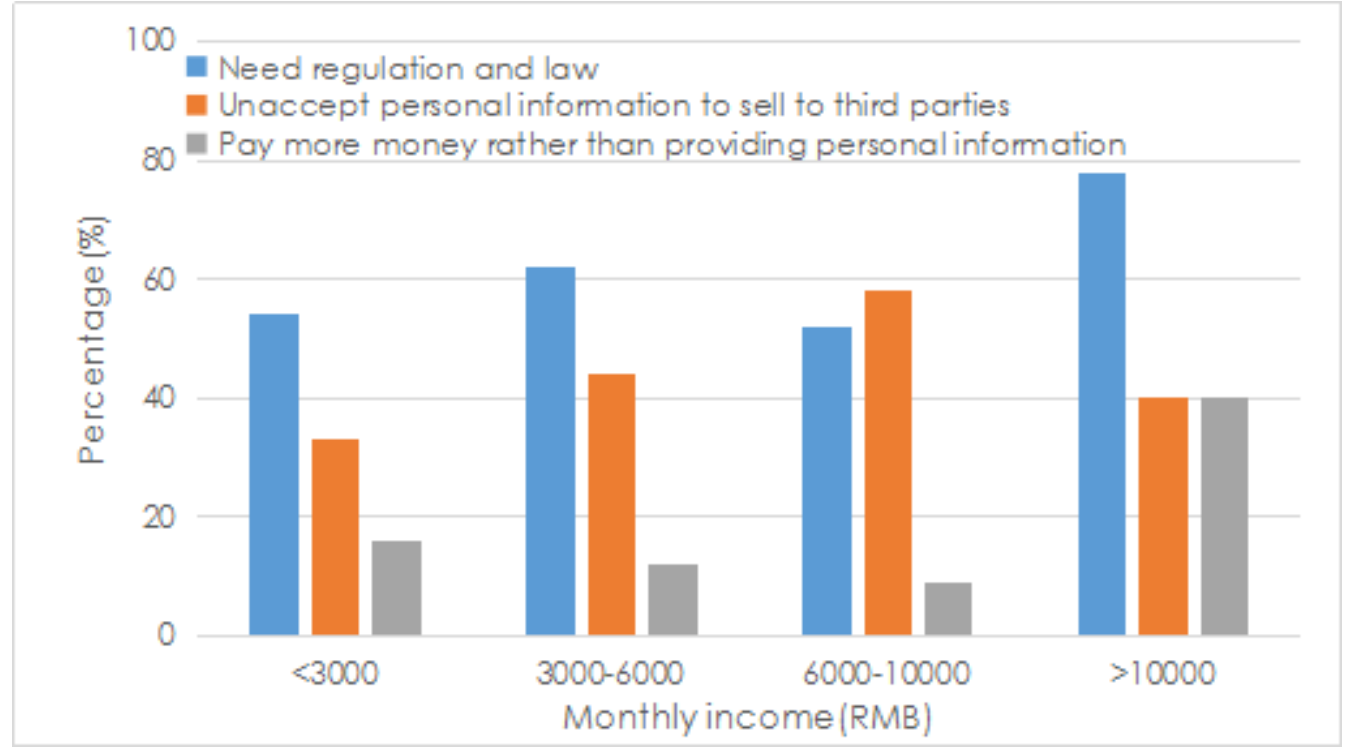

Figure. 1 The attitude for privacy of different income groups.

\section{Research on Social Psychology Employing the Big Data}

There are many researchers have focused on some practical experimental researches employing the big data, such as, Peng Kaiping, Tsinghua University Professor, has established the "behavior and large data research laboratory", and Cai Huajian, professor of the Chinese Academy of Sciences Institute of Psychology has created a "cloud of psychological laboratories", and professor Zhu Ting Shao has developed "people psychological map" based on big data. Besides, some blog-related newly development has been carried out.

The first is the risk social forecast. China's society, which is in the process of social transformation and globalization, faces various social risks. Some of the emotions of the public may lead to some social collective activities. However, due to the means of measurement and cost constraints, the relationship between public perception of social risk and social sentiment is not clear. We can find that the social risk of public perception has a significant predictive power to social sentiment. From the perspective of the microblogging emotional analysis, a comprehensive 
analysis has been performed with the help of a micro-blog basic emotional lexicon tool. Table 1 shows the word numbers of emotional dictionary. There are seven different types of emotion. We investigated the five different industries of 500 microblogging elite and 10,000 microblogging public users between the microblogging emotional relationship. These industries include education, entertainment, computers, real estate and so on. The results of the survey analysis are shown in Table 2. We found that China's current economic capital has a greater influence than cultural capital. The field of economic capital has a tendency to prevail over public sentiment, and the tendency of leading public sentiment in the field of cultural capital is relatively low, even behind the public sentiment. In addition, we also found that negative emotions are more likely to spread than positive emotions, and that the relationship between different areas and different emotional types is not exactly the same.

Table 1 The number of different emotions in the blog-emotional tool.

\begin{tabular}{|c|c|c|c|c|c|c|c|}
\hline $\begin{array}{c}\text { Emotional } \\
\text { Type }\end{array}$ & Angry & Surprised & Happy & Hate & Sad & Fear & Like \\
\hline Number & 341 & 9001 & 1456 & 3402 & 2389 & 1203 & 12098 \\
\hline
\end{tabular}

Table 2 The emotional situation of different industries.

\begin{tabular}{|c|c|c|c|c|c|}
\hline Percentage(\%) & Education & Property & Entainment & Computer & Economy \\
\hline $\begin{array}{c}\text { Positive } \\
\text { Emotion }\end{array}$ & 70 & 43 & 51 & 68 & 45 \\
\hline $\begin{array}{c}\text { Passive } \\
\text { Emotion }\end{array}$ & 34 & 51 & 65 & 24 & 67 \\
\hline
\end{tabular}

\section{Summary}

In recent years, the social psychology research based on the network big data has shown great development potential, and made great breakthrough in the research perspective, the diversed research methods and so on. However, for domestic researchers, the domestic research in related fields is still in the exploratory period, and the research results and experience is relatively small. Therefore, this means that there is a vast space for development, at the same time, it also means the enormous challenges. It is suggested that the future research should be applied to solve the social problems with important practical significance. Researchers themselves should be able to take the initiative to learn and understand the relevant areas of knowledge, to break the boundaries of traditional disciplines of thinking, and they are actively engaged in interdisciplinary cooperation in practice, so as to grasp the opportunities of network big data.

\section{References}

[1] Sherif M. Group conflict and co-operation: Their social psychology[M]. Psychology Press, 2015.

[2] Gandomi A, Haider M. Beyond the hype: Big data concepts, methods, and analytics[J]. International Journal of Information Management, 2015, 35(2): 137-144.

[3] Fox J, Moreland J J. The dark side of social networking sites: An exploration of the relational and psychological stressors associated with Facebook use and affordances[J]. Computers in Human Behavior, 2015, 45: 168-176.

[4] Impression management theory and social psychological research[M]. Academic Press, 2013.

[5] Smith E R, Mackie D M, Claypool H M. Social psychology[M]. Psychology Press, 2014.

[6] Cavoukian A, Jonas J. Privacy by design in the age of big data[M]. Information and Privacy Commissioner of Ontario, Canada, 2012. 
[7] Tene O, Polonetsky J. Big data for all: Privacy and user control in the age of analytics[J]. Nw. J. Tech. \& Intell. Prop., 2012, 11: xxvii. 